\title{
Allergic Rhinitis and Pharmacological Management in Elite Athletes
}

\author{
Alaranta, A. \\ Lippincott, Williams \& Wilkins \\ 2005
}

Medicine \& Science in Sports \& Exercise. 2005. 37(5): 707-711

http://hdl.handle.net/1975/733

Downloaded from Helda, University of Helsinki institutional repository.

This is an electronic reprint of the original article.

This reprint may differ from the original in pagination and typographic detail.

Please cite the original version. 


\title{
Allergic Rhinitis and Pharmacological Management in Elite Athletes
}

\author{
ANTTI ALARANTA ${ }^{1}$, HANNU ALARANTA ${ }^{2}$, MARKKU HELIÖVAARA ${ }^{3}$, PIRKKO ALHA ${ }^{3}$, PETRI PALMU ${ }^{4}$, and \\ ILKKA HELENIUS ${ }^{5}$ \\ ${ }^{1}$ Faculty of Pharmacy, University of Helsinki, Helsinki, FINLAND; ${ }^{2}$ Käpylä Rehabilitation Centre, Helsinki, FINLAND; \\ ${ }^{3}$ National Public Health Institute, Helsinki, FINLAND; ${ }^{4}$ Faculty of Social Sciences, University of Helsinki, Helsinki, \\ FINLAND; and ${ }^{5}$ Hospital for Children and Adolescents, Helsinki University Central Hospital, Helsinki, FINLAND
}

\begin{abstract}
AlARANTA, A., H. AlARANTA, M. HEliöVAARA, P. ALHA, P. PALMU, and I. HELENIUS. Allergic Rhinitis and Pharmacological Management in Elite Athletes. Med. Sci. Sports Exerc., Vol. 37, No. 5, pp. 707-711, 2005. Introduction: Only a few studies have examined the occurrence of atopy and clinically apparent allergic disease and their pharmacological management in elite athletes. The aim of the study was to assess the frequency of allergic rhinitis and the use of antiallergic medication within the subgroups of elite athletes as compared with a representative sample of young adults of the same age. Methods: A cross-sectional survey was carried out in 2002. All the athletes $(N=494)$ financially supported by the National Olympic Committee comprised the study group. Of them, $446(90.3 \%)$ filled in a structured questionnaire concerning asthma and allergies, the use of medication, characteristics of sport activities, and smoking habits. A representative sample of Finnish young adults $(N=1504)$ served as controls. Results: The endurance athletes reported physician-diagnosed allergic rhinitis more often (36.1\%) than other athletes $(23.4 \%)$ or control subjects $(20.2 \%)$. The use of antiallergic medication was reported by $33.3,15.7$, and $15.6 \%$ of those, respectively. Among both athletes and controls, females reported the use of antiallergic medication more often than males. Only half of those athletes reporting allergic rhinitis had used antiallergic medication during the past year. After adjusting for age and sex, OR (95\% CI) for allergic rhinitis and the use of antiallergic medication were 2.24 (1.48-3.39) and 2.79 (1.82-4.28), respectively, in endurance athletes as compared with the controls. Conclusions: Endurance athletes have physician-diagnosed allergic rhinitis, and they use antiallergic medication more often than athletes in other events or control subjects. Only half of those athletes reporting allergic rhinitis take antiallergic medication. More attention needs to be paid to the optimal management of allergic rhinitis, especially in highly trained endurance athletes. Key Words: ANTIALLERGIC MEDICATION, ALLERGIC RHINOCONJUNCTIVITIS, ANTIHISTAMINES, INTRANASAL CORTICOSTEROIDS, ENDURANCE ATHLETE
\end{abstract}

$\mathrm{S}$ port exercise may increase ventilation up to 200 $\mathrm{L} \cdot \mathrm{min}^{-1}$ for short periods of time in speed and power athletes and for longer periods in endurance athletes (8). When the ventilation level exceeds about $30 \mathrm{~L} \cdot \mathrm{min}^{-1}$, a shift occurs from nasal breathing to combined mouth and nasal breathing (3). This shift results in a greater deposition of airborne allergens and other inhaled particles into the athlete's lower airways; in addition, incompletely conditioned air may reach the mucous membranes of the lower airways (18). Athletes who participate in summer events are

\footnotetext{
Address for correspondence: Antti Alaranta, M.Sc. (Pharm), Tammelankatu 8 B 10, FIN-04430 Järvenpää, Finland; E-mail: antti.alaranta@helsinki.fi. Submitted for publication September 2004.

Accepted for publication December 2004.
}

\section{5-9131/05/3705-0707}

MEDICINE \& SCIENCE IN SPORTS \& EXERCISE ${ }_{\circledast}$

Copyright (C) 2005 by the American College of Sports Medicine

DOI: $10.1249 / 01 . M S S .0000162689 .69517 .60$ intensively exposed to airborne allergens during their training and competitions, whereas winter sport athletes are exposed to cold air (20). Swimmers are exposed to chlorine compounds. In skiers $(8,15,19)$, the association between atopy, respiratory allergy, and asthma has not been demonstrated to be as clear as in summer sport athletes $(9,10)$. Indeed, allergic rhinitis (AR) and atopy are more common in endurance athletes competing in summer events as compared with control subjects (9), whereas the occurrence of atopy in skiers is similar as in control subjects (19).

Nasal mucosal swelling may lead to compromised drainage of the related anatomical systems, which may lead to acute or chronic infection (13). Chronic AR is associated with many complications. Nasal obstruction on a long-term basis often leads to snoring, sleep disturbance, headaches, and fatigue, all of which will impair a person's quality of life. Impaired sleep, together with irritability caused by this condition, can have a significant impact on a person's quality of life by leading to poor performance and chronic 


\begin{tabular}{lccccc}
\hline & $\begin{array}{c}\text { All Athletes } \\
(\boldsymbol{N}=\mathbf{4 4 6 / 4 9 4 )}\end{array}$ & $\begin{array}{c}\text { Speed and Power } \\
\text { Events }(\boldsymbol{N}=\mathbf{1 1 3})\end{array}$ & $\begin{array}{c}\text { Endurance Events } \\
(\boldsymbol{N}=\mathbf{1 0 8})\end{array}$ & $\begin{array}{c}\text { Motor } \\
\text { Skills-Demanding } \\
\text { Events }(\boldsymbol{N}=\mathbf{7 3})\end{array}$ & $\begin{array}{c}\text { Team Sport } \\
\text { Events }(\boldsymbol{N}=\mathbf{1 5 2})\end{array}$ \\
$(\boldsymbol{N}=\mathbf{1 5 0 4 / 1 8 7 6})$
\end{tabular}

tiredness. When AR affects elite athletes, however, these quality-of-life issues make it particularly troublesome, and it may cause significant impairment in their athletic performances. During exercise, minute ventilation increases, which brings the nasal passages into contact with greater volumes of air and therefore allergens, so symptoms are commonly experienced during exercise. For example, a short burst of sprinting requires combined mouth and nasal breathing for optimal performance, so a change in the individual's pattern of breathing because of nasal obstruction may affect performance. Untreated AR may also compromise the treatment of asthma in elite athletes (4). Furthermore, several studies have shown that AR is underrecognized and certainly undertreated in elite athletes $(7,14)$. It has been suggested that strong and repeated exposure to airborne allergens causes not only bronchial symptoms but also AR in elite summer sport athletes (20).

The pharmacological management of AR has to comply with antidoping regulations. The goal of the therapy is optimum symptom control while minimizing the detrimental influences on performance from adverse effects. Recently, caffeine, pseudoephedrine, and phenylpropanolamine were declassified by the WADA. This facilitates the pharmacological care of AR in elite athletes and removes the concern for the positive test results when these substances are used unintentionally for the management of AR. The results of the IOC accredited laboratories show that nearly one third of the positive results for stimulants were for these three substances in 2002 (IOC statistics 2002, Overview on the results reported by the IOC accredited laboratories, http://multimedia.olympic.org/pdf/en_report_632.pdf).

Whereas the impact of exercise-induced asthma and increased bronchial responsiveness on athletes' performance has been studied extensively, only a few studies have examined the occurrence of atopy and clinically apparent allergic disease and their pharmacological management in elite athletes. The aim of the study was to assess the frequency of AR, other allergic conditions, and the use of antiallergic medication within the different groups of sport activities in a large sample of Finnish top elite athletes. These athletes were also compared with a representative sample of young adults of the same age.

\section{METHODS}

Study design for athletes. A cross-sectional questionnaire survey was carried out in 2002. All athletes $(N=$ 494) eligible for financial support of National Olympic Committee comprised the source population for this study.
They were asked to complete the questionnaire at their national team camps during the study period, and if they were absent, the questionnaire was sent to them by mail. Of the 494 athletes, 446 (90.3\%) filled in a structured questionnaire after accepting written informed consent. The athletes were divided into four groups according to their type of sport. The four groups were speed and power sport athletes, endurance athletes, athletes in motor skills demanding events, and team sport athletes. The characteristics of the four study groups are given in the Table 1 . The inclusion criteria and methods employed have been described in details previously in this journal (1).

Control subjects. The reference group consisted of all persons aged $18-29$ yr $(N=1894)$ from the Finnish National Health Survey Health 2000, coordinated by the National Public Health Institute. A nationally representative two-stage cluster sample was drawn, which consisted of 10,000 persons and 80 regions (municipalities or groups of municipalities with joint primary care). The sample included inhabitants of all the 15 largest cities and towns. The substudy of younger adults aged 18-29 consisted of a computer-aided health interview carried out during the spring and summer of 2001. The final size of the sample of those aged 18-29 was 1876, of which 1504 (80.2\%) participated in the health interview. The data was collected, stored, analyzed, and reported anonymously according to the law of data protection in Finland.

Questionnaire. Questions concerned asthma, exerciseinduced bronchial symptoms, the use of asthma and allergy medication, the characteristics of sport activities, educational level, and smoking habits (1). The subjects were asked whether they had a disturbing allergy that had been diagnosed by a physician. When the subject responded affirmatively to the question, the subject was further asked whether the condition was AR, allergic conjunctivitis, atopic eczema, or other. The subjects were also asked whether they had any current medication for their condition. If they had, they were asked to list all the preparations used during the previous 12 months. The subjects were further asked whether they used above mentioned medication regularly or as needed. In addition, they were asked if they had taken these preparations during the last $7 \mathrm{~d}$ (yes/no).

In the results section, sympathomimetics include products containing phenylpropanolamine or pseudoephedrine. Antiallergic nasal sprays without corticosteroids include products containing disodium cromoglycate or levocabastine.

Statistical methods. The odds ratios (OR) for AR and atopic eczema and their $95 \%$ confidence intervals $(95 \% \mathrm{CI})$ for athlete subgroups compared with controls were analyzed 
TABLE 2. Prevalence (\%) of physician-diagnosed disturbing allergy, AR, allergic conjunctivitis, and atopic eczema in the study groups.

\begin{tabular}{llll}
\hline & $\begin{array}{c}\text { Disturbing } \\
\text { Allergy }\end{array}$ & $\begin{array}{c}\text { Allergic } \\
\text { Rhinitis }\end{array}$ & $\begin{array}{c}\text { Allergic } \\
\text { Conjunctivitis }\end{array}$ \\
\hline Eczema
\end{tabular}

using a logistic regression model (SPSS 10.0 software). Age, sex, and type of sport were included as independent covariates in the analysis.

The sample-size requirement was calculated using a study power of $80 \%$, a Type I error $\alpha$ of 0.05 , and an estimated prevalence of 25 and $15 \%$ for AR in the athlete and control group, respectively (9). A total of 249 study subjects in both groups were required to identify a $10 \%$ difference in prevalence rates between these groups.

\section{RESULTS}

No statistical difference was found in the occurrence of a disturbing allergy (32.1 vs $30.1 \%$; Table 2 ), or in the ageand sex-adjusted OR between athletes and controls (OR, 1.12; 95\% CI, 0.89-1.41). A physician-diagnosed AR was reported by $26.5 \%$ (118 of 446) of the athletes and by $20.2 \%$ (303 of 1503) of the controls (Table 2). After adjusting for age and sex, the OR $(95 \% \mathrm{CI})$ for physician diagnosed AR was significantly higher among endurance athletes as compared with controls (OR, 2.24; 95\% CI, 1.48-3.39; Table 4).

The athletes reported the use of antiallergic medication significantly more often than the controls did (20.0 vs $15.6 \%$; OR, 1.42; 95\% CI, 1.08-1.87). A total of $12.6 \%$ (56 of 446) of the athletes and 6.3\% (94 of 1503) of the controls reported using antiallergic medication during the last $7 \mathrm{~d}$. Of the athletes $4.9 \%$ (34/446) and 2.3\% (34/1 503 ) of the controls reported using antiallergic medication regularly. After adjusting for age, and sex, the OR for the use of any antiallergic medication was significantly higher among endurance athletes than for the controls (OR, 2.79; 95\% CI, 1.82-4.28; Table 4). No significant difference existed between winter and summer sport athletes in AR or use of medication.

Allergic conjunctivitis was reported by $3.6 \%$ of the athletes and $5.6 \%$ of the controls. The women, both the athletes and controls, reported this condition more often than the men (Table 2). In both groups, the women used antiallergic eyedrops more often than men did (Table 3 ).

The most commonly used antiallergy drugs in all study groups were oral antihistamines, followed by intranasal corticosteroids. A significant difference was observed in the frequency of oral antihistamine use between different sport events, with the endurance athletes reporting treatment most often. After adjusting for age, and sex, the OR (95\% CI) for the use of oral antihistamines was significantly higher among endurance athletes than in the general population (OR, 2.52; 95\% CI, 1.54-4.12, Table 4). Among those with a history of any allergy, no significant difference in the use of antiallergic medication was found between various groups of athletes and the general population.

A total of $55.1 \%$ (65 of 118) of those athletes and $53.5 \%$ (162 of 303) of the controls having physiciandiagnosed rhinitis reported using antiallergic medication. Female athletes with physician diagnosed AR used antiallergic medication more often than male athletes (65.3\% (32 of 49 ) vs $47.8 \%$ (33 of 69)). Of the athletes reporting AR, 34.7\% (41 of 118) also had physician-diagnosed asthma, whereas $6.4 \%$ (21 of 328) of those athletes who did not report AR had asthma.

TABLE 3. Prevalence (\%) of the use of antiallergic medication during the previous 12 months.

\begin{tabular}{|c|c|c|c|c|c|c|}
\hline & $\begin{array}{c}\text { Oral } \\
\text { Antihistamines }\end{array}$ & $\begin{array}{c}\text { Intranasal } \\
\text { Corticosteroids }\end{array}$ & Sympathomimetcs & $\begin{array}{c}\text { Antiallergic Nasal } \\
\text { Sprays without } \\
\text { Corticosteroids }\end{array}$ & $\begin{array}{l}\text { Antiallergic } \\
\text { Eyedrops }\end{array}$ & $\begin{array}{l}\text { Any } \\
\text { Antiallergic } \\
\text { Drug }\end{array}$ \\
\hline All athletes & $13.7(61 / 446)$ & $6.1(27 / 446)$ & $1.3(6 / 446)$ & $1.3(6 / 446)$ & $2.2(10 / 446)$ & $20.0(89 / 446)$ \\
\hline Summer events & $13.5(36 / 266)$ & $4.9(13 / 266)$ & $2.3(6 / 266)$ & $0.4(1 / 266)$ & $1.5(4 / 266)$ & $18.0(48 / 266)$ \\
\hline Winter events & $13.9(25 / 180)$ & $7.8(14 / 180)$ & 0 & $2.8(5 / 180)$ & $3.3(6 / 180)$ & $22.8(41 / 180)$ \\
\hline Speed and power athletes & $11.5(13 / 113)$ & $5.3(6 / 113)$ & $2.7(3 / 113)$ & $0.9(1 / 113)$ & $1.8(2 / 113)$ & $16.8(19 / 113)$ \\
\hline Team sport athletes & $10.5(16 / 152)$ & $5.9(9 / 152)$ & 0 & $1.3(2 / 152)$ & $2.0(3 / 152)$ & $16.4(25 / 152)$ \\
\hline Controls & $11.0(166 / 1503)$ & $3.6(54 / 1503)$ & $3.1(46 / 1503)$ & $0.5(7 / 1503)$ & $1.8(27 / 1503)$ & $15.6(235 / 1503)$ \\
\hline Women & $11.9(88 / 738)$ & $4.7(35 / 738)$ & $3.9(29 / 738)$ & $0.5(4 / 738)$ & $2.4(22 / 738)$ & $17.5(129 / 738)$ \\
\hline Men & $10.2(78 / 765)$ & $2.5(19 / 765)$ & $2.2(17 / 765)$ & $0.4(3 / 765)$ & $0.7(5 / 765)$ & $13.9(106 / 1503)$ \\
\hline
\end{tabular}


TABLE 4. Logistic regression model on physician-diagnosed disturbing allergy, AR, and antiallergic medication used during the previous 12 months after adjusting for age and sex.

\begin{tabular}{|c|c|c|c|c|c|c|c|c|c|c|}
\hline \multirow[b]{2}{*}{ Characteristic } & \multicolumn{2}{|c|}{ Disturbing Allergy } & \multicolumn{2}{|c|}{ Allergic Rhinitis } & \multicolumn{2}{|c|}{ Oral Antihistamines } & \multicolumn{2}{|c|}{$\begin{array}{c}\text { Intranasal } \\
\text { Corticosteroids }\end{array}$} & \multicolumn{2}{|c|}{$\begin{array}{l}\text { Any Antiallergic } \\
\text { Medication }\end{array}$} \\
\hline & OR & $95 \% \mathrm{Cl}$ & OR & $95 \% \mathrm{Cl}$ & OR & $95 \% \mathrm{Cl}$ & OR & $95 \% \mathrm{Cl}$ & OR & $95 \% \mathrm{Cl}$ \\
\hline \multicolumn{11}{|l|}{ Age (yr) } \\
\hline Under 21 & 1 & & 1 & & 1 & & 1 & & 1 & \\
\hline $21-24$ & 1.07 & $0.83-1.37$ & 1.04 & $0.79-1.37$ & 1.27 & $0.87-1.84$ & 0.65 & $0.35-1.21$ & 1.18 & $0.86-1.62$ \\
\hline Over 24 & 1.17 & $0.91-1.49$ & 1.07 & $0.81-1.41$ & 1.33 & $0.92-1.92$ & 1.49 & $0.88-2.52$ & 1.33 & $0.98-1.81$ \\
\hline \multicolumn{11}{|l|}{ Sex } \\
\hline Women & 1 & & 1 & & 1 & & 1 & & 1 & \\
\hline Men & 0.96 & $0.79-1.17$ & 0.99 & $0.80-1.23$ & 0.78 & $0.59-1.04$ & 0.50 & $0.32-0.79$ & 0.69 & $0.54-0.88$ \\
\hline \multicolumn{11}{|l|}{ Type of sports } \\
\hline None (controls) & 1 & & 1 & & 1 & & 1 & & 1 & \\
\hline Speed and power athletes & 0.89 & $0.58-1.38$ & 1.01 & $0.63-1.63$ & 1.07 & $0.58-1.97$ & 1.69 & $0.70-4.06$ & 1.18 & $0.70-1.98$ \\
\hline Endurance athletes & 1.79 & $1.21-2.67$ & 2.24 & $1.48-3.39$ & 2.52 & $1.54-4.12$ & 2.75 & $1.35-5.58$ & 2.79 & $1.82-4.28$ \\
\hline Motor skill-demanding events & 1.33 & $0.81-2.19$ & 1.51 & $0.89-2.56$ & 0.76 & $0.32-1.79$ & 0.77 & $0.18-3.22$ & 0.81 & $0.40-1.66$ \\
\hline Team sport athletes & 0.82 & $0.56-1.21$ & 1.25 & $0.84-1.89$ & 0.92 & $0.57-1.71$ & 1.60 & $0.77-3.34$ & 1.11 & $0.70-1.74$ \\
\hline
\end{tabular}

\section{DISCUSSION}

Untreated AR may severely weaken athletes' maximal exercise performance. In accordance with that fact and previous studies, the current study showed that physiciandiagnosed AR and the use of antiallergic medication are significantly more prevalent in the elite endurance athletes than among other athletes or the general population. However, the prevalence of allergic conditions other than AR did not differ between various groups of athletes and the general population. Nearly half of the athletes with an AR diagnosis did not take antiallergic medication. Thus, undertreatment may also be a problem for elite athletes.

Validity of the data. A structured questionnaire was used to evaluate the prevalence of AR and the use of antiallergic medication by elite athletes as compared with a large control population representing Finnish people of the same age. Response rate was excellent exceeding $90 \%$ for the athletes and $80 \%$ for the control subjects. The samplesize requirement was calculated using study power of $80 \%$ and Type I $\alpha$ error of 0.05 . This gave 249 study subjects in both groups, which we managed to recruit.

In the present study, 20\% of the control population reported having a physician-diagnosed AR. This corresponds well with a previous study in our country. According to Vartiainen et al. (21), a lifetime history of hay fever was reported by $21.9 \%$ of the random sample population of 25- to 54-yr-old subjects living in North Karelia, Finland. The principal aim of this study was to evaluate use of antiallergic medication in Finnish elite athletes as compared with people at large. Use of skin-prick testing for all athletes and controls would have increased obtained information. However, this would have required nearly 2000 skin-prick tests in the present study, which obviously is not possible. Previously, Helenius et al. $(9,11)$ have shown that the occurrence of atopic allergy according to skin-prick tests is much higher than self-reported physician diagnosed AR. In addition, clinical pollen allergy (positive skin test to pollen allergens and symptoms of allergic rhinoconjunctivitis) coincides extremely well with self-reported physician diagnosed AR $(9,11)$.

Most of the winter sport athletes represent Caucasian white populations. In addition, the athletes practice and compete mostly in the same locations all year round in order to be able to do training on snow. The authors believe that the results obtained here for winter sport athletes are well generalized to all winter sport athletes. However, summer sport athletes represent a more culturally and ethnically diverse population. Thus, the results of summer sport athletes obtained here should be generalized with caution. It can be argued that these athletes live in the health system that enhances the identification of AR and subsequent treatment. However, both controls and athletes live in a similar society. In addition, the prevalence of AR was very similar between controls and athletes in other than endurance events.

Comparison with earlier studies. Helbling et al. (7) surveyed 2961 elite Swiss athletes (response rate 70\%) participating in 68 sports. A total of $16.8 \%$ of the athletes indicated that they had AR, and of these 59\% needed medication during the pollen season. In the present study, $26.5 \%$ of the athletes reported AR, with 55\% having medication for it.

Helenius et al. (9) found that clinical pollen allergy (a positive skin-prick test (SPT) and symptoms of seasonal allergic rhinoconjunctivitis (ARC) affected one third of the endurance athletes competing in summer events. Katelaris et al. (13) determined the incidence of seasonal ARC in a large sample of Australian elite athletes $(N=977)$. Of these, 49.5\% had symptoms of ARC, $23 \%$ a history of asthma, and $10 \%$ of eczema. A total of $56 \%$ had a positive SPT to at least one allergen tested, and 34\% to at least one seasonal allergen. Of the athletes, $25 \%$ met the criteria for a diagnosis of seasonal ARC (a positive SPT to at least one seasonal allergen and the presence of at least two symptoms of ARC).

Maiolo et al. (17) studied asthma and atopy in 1060 Italian athletes who were trying out for a position on the Italian Olympic Team for the Sydney 2000 Olympic Games. Of the studied athletes, $18.3 \%$ reported symptoms of atopy. No significant gender differences were observed. A total of $14.5 \%$ of the athletes reported being diagnosed for AR ( $15.5 \%$ of the males and $12.3 \%$ of the females). Symptoms of rhinitis were more frequent in the subgroup of endurance athletes than in the other groups. These findings correspond well with our results and can be explained by the athletes' increased exposure to airborne allergens especially in en- 
durance events (9). In contrast, the prevalence of allergic conjunctivitis did not differ between athletes and controls in the present study. This could be explained by the fact that athletes' conjunctivas do not receive such an increase of airborne allergens as airway mucosal lining membrane does.

The upper respiratory tract functions as a physical filter, heat exchanger, and humidifier for inhaled air. Thus, alteration of upper airway function is expected to result in alteration of lower airway function. According to Volcheck (22), AR should be carefully assessed and aggressively controlled in order to prevent the development of asthma or as integral part of asthma treatment. Several epidemiologic studies have shown an association between AR and asthma (16). Guerra et al. (6) reported, after controlling for age, sex, smoking status, and atopic status, that rhinitis increased the risk of asthma threefold. In the allergy report from the American Academy of Allergy, Asthma, and Immunology, it was estimated that up to $38 \%$ of patients with AR have asthma (2). In the present study, 34.7\% of the athletes with AR reported having asthma, whereas only $6.4 \%$ of the athletes not reporting AR had asthma.

Pharmacological management. No studies have evaluated in detail the use of antiallergic medication by elite athletes. Treatment of AR could include avoiding allergens (usually not possible for athletes), taking intranasal corticosteroids, short-term decongestants, oral or topical $\mathrm{H}_{1}$ receptor antago-

\section{REFERENCES}

1. Alaranta, A., H. Alaranta, P. Palmu, et al. Asthma medication in Finnish Olympic athletes: no signs of inhaled $\beta_{2}$-agonist overuse. Med. Sci. Sports Exerc. 36:919-924, 2004.

2. American Academy of Allergy, Asthma, and Immunology. The Allergy Report: Overview of Allergic Diseases: Diagnosis, Management, and Barriers to Care, Vol. 1. Milwaukee: American Academy of Allergy, Asthma, and Immunology, 2000, pp. 25-45.

3. Anderson, S. D., and A. G. Togias. Dry air and hyperosmolar challenge in asthma and rhinitis. In: Asthma and Rhinitis, W. W. Busse and S. T. Holgate (Eds.). Boston: Blackwell Scientific Publications, 1995, pp. 1178-1195.

4. Bousquet, J., P. VAn CAuwenberge, C. Bachert, et al. Requirements for medications commonly used in the treatment of allergic rhinitis. European Academy of Allergy and Clinical Immunology (AACI): allergic rhinitis and its impact on asthma (ARIA). Allergy 58:192-197, 2003.

5. Carrozzi, F. M., C. H. Katelaris, T. V. Burke, and K. Byth. An open study examining the effects of intranasal budesonide on quality of life and performance in elite athletes with allergic rhinoconjunctivitis. J. Allergy Clin. Immunol. 107:S154-S155, 2001.

6. Guerra, S., D. L. Sherrill, F. D. Martinez, and R. A. Barbee. Rhinitis as an independent risk factor for adult-onset asthma. J. Allergy Clin. Immunol. 109:419-425, 2002.

7. Helbling, A., P. Jenoure, and U. Muller. The incidence of hay fever in leading Swiss athletes. Schweiz. Ned. Wochenschr. 120: 231-236, 1990.

8. Helenius, I., and T. HaAhtela. Allergy and asthma in elite summer sport athletes. J. Allergy Clin. Immunol. 106:444-452, 2000.

9. Helenius, I. J., H. O. Tikkanen, S. Sarna, and T. HaAhtela. Asthma and increased bronchial responsiveness in elite athletes: atopy and sport event as risk factors. J. Allergy Clin. Immunol. 101:646-652, 1998.

10. Helenius, I. J., H. O. Tikkanen, and T. HaAhtela. Occurrence of exercised-induced bronchospasm in elite runners: dependence on atopy and exposure to cold air and pollen. Br. J. Sports Med. 32: 125-129, 1998.

11. Helenius, I. J., H. O. Tikkanen, and T. HaAhtela. Association between type of training and risk of asthma in elite athletes. Thorax 52:157-160, 1997. nists (antihistamines), intranasal cromoglycate, anticholinergic agents, or by undergoing allergen immunotherapy (12).

Weiner et al. (23) conducted a meta-analysis of 16 evaluable trials. Their analysis strongly indicates that intranasal corticosteroids are significantly more effective at relieving nasal blockage, discharge, itch, and postnasal drip than are oral antihistamines. Intranasal corticosteroids were also more effective at relieving sneezing and in reducing total nasal symptoms than were the oral antihistamines, but there was significant heterogeneity between the studies. Carrozzi et al. (5) reported that preventive treatment with intranasal corticosteroids, significantly improved symptoms of AR, quality of life, and performance of Australian elite athletes. In the present study, $6 \%$ of the athletes and $3.6 \%$ of the control subjects reported they had used intranasal corticosteroids.

In conclusion, endurance athletes have physician-diagnosed $\mathrm{AR}$, and they use antiallergic medication more often than athletes in other events or control subjects. Female athletes use antiallergic medication more frequently than male athletes. Only half of those athletes reporting AR take antiallergic medication. More attention thus needs to be paid to the optimal management of AR in highly trained athletes.

The study was supported by Finnish National Olympic Committee, Finnish Ministry of Education, and Finnish Sports Research Foundation.

12. International Rhinitis Management Working Group. International consensus report on the diagnosis and management of rhinitis. Allergy 49:1-34, 1994.

13. Katelaris, C. H., F. M. Carrozzi, and T. V. Burke. Allergic rhinoconjunctivitis in elite athletes: optimal management for quality of life and performance. Sports Med. 33:401-406, 2003.

14. Katelaris, C. H., F. M. Carrozzi, T. V. Burke, and K. Byth. A springtime Olympics demands special consideration for allergic athletes. J. Allergy Clin. Immunol. 106:260-266, 2000.

15. Larsson, K., P. Ohlsen, L. Larsson, P. Malmberg, P. Rydström, and H. UlRIKSEN. High prevalence of asthma in cross-country skiers. Br. Med. J. 307:1326-1329, 1993.

16. Leynaert, B., F. Neukirch, P. Demoly, and J. Bousquet. Epidemiologic evidence for asthma and rhinitis comorbidity. J. Allergy Clin. Immunol. 106:S201-S205, 2000.

17. Maiolo, C., L. Fuso, A. Todaro, et al. Asthma and atopy in elite athletes. Int. J. Sports Med. 24:139-144, 2003.

18. McFadden, E. R. Jr., B. M. Pichurko, H. F. Bowman, et al. Thermal mapping of the airways in humans. J. Appl. Physiol. 58:564-570, 1985.

19. Sue-Chu, M., L. Larsson, and L. Bjermer. Prevalence of asthma in cross-country skiers in central Scandinavia: differences between Norway and Sweden. Respir. Med. 90:99-105, 1996.

20. Tikkanen, H. O., and I. J. Helenius. Asthma in runners (letter) Br. Med. J. 309:1087, 1994.

21. Vartiainen, E., T. Petäys, T. Hahhtela, P. Jousilahti, and J. PekKanen. Allergic diseases, skin prick test responses, and IgE levels in North Karelia, Finland, and the Republic of Karelia, Russia. J. Allergy Clin. Immunol. 109:643-648, 2002.

22. Volcheck, G. W. Does rhinitis lead to asthma? Evidence for the one-airway hypothesis. Postgrad. Med. 115:65-68, 2004.

23. Weiner, J. M., M. J. Abramson, and R. M. Puy. Intranasal corticosteroids versus oral $\mathrm{H}_{1}$ receptor antagonists in allergic rhinitis: systemic review of randomised controlled trials. Br. Med. J. 317: 1624-1629, 1998. 